\title{
Sistema Laban/Bartenieff e Coordenação Motora em Aulas de Balé Clássico na Formação do(a) Artistadocente de Dança
}

\author{
Neila Cristina Baldi \\ Universidade Federal de Santa Maria - UFSM, Santa Maria/RS, Brasil \\ E-mail: neila.baldi@ufsm.br
}

\section{Resumo}

Este texto discute uma proposta metodológica de aprenderensinar balé clássico que se utiliza das abordagens somáticas Coordenação Motora e Sistema Laban/Bartenieff. A proposição aqui apresentada foi desenvolvida com estudantes de graduação em Dança e fez parte de pesquisa de Doutorado defendida em 2017. Desta forma, o texto se propõe a pensar como as abordagens somáticas e os princípios somáticos estão presentes na formação do(a) artistadocente de dança.
This text discusses a methodological proposal to learnteach classical ballet using the somatic approaches Motor Coordination and the Laban/Bartenieff System. The proposition presented here was developed with undergraduate students in Dance and was part of a doctoral research advocated in 2017. In this way, the text proposes to think how the somatic approaches and principles are present in the formation of the teacherartist of dance.

Somatic Approaches. Ballet. Motor Coordination. Laban/Bartenieff System. Teacherartist. 


\section{Introdução}

A graduação em Dança é um dos espaços formativos para o(a) artistadocente hoje no Brasil. Atualmente, são 40 cursos em funcionamento, entre bacharelados e licenciaturas (MINISTÉRIO DA EDUCAÇÃO, 2020), sendo a maior parte licenciaturas. E, em cerca de 1/3 (BALDI, 2016), a Educação Somática faz parte do currículo ou permeia a ação dos(as) professores(as). Mas como a Educação Somática ajuda na formação do artistadocente ${ }^{1}$ de dança? Em que ela contribui?

Este texto discute algumas questões sobre a formação do(a) artistadocente, levantadas na pesquisa de Doutorado em Artes Cênicas, realizada na Universidade Federal da Bahia (UFBA), sobre aprenderensinar ${ }^{2}$ balé clássico a partir do Sistema Laban/ Bartenieff e da Coordenação Motora (de Marie-Madeleine Béziers, Suzanne Piret e Yva Hunsinger ${ }^{3}$ ).

As proposições foram desenvolvidas no componente curricular Técnica do Corpo II - Dança Clássica, com 75 horas-aula, distribuídas em dois dias se-

$1 \mathrm{Na}$ minha avaliação, o hífen que separaria as duas profissões pode dar uma indicação dicotômica para esta formação. Concordo com o argumento da indissociação das atividades de artista e docente, como proposto por Icle (2012, p. 17-18): "O professor-artista não seria uma soma de professor mais artista. Ele seria 100\% artista e $100 \%$ professor. Não se trata de uma volta à tradição de se aprender arte com um artista. Mas longe de assumir o papel distanciado de quem acompanha o trabalho de seus alunos, ele próprio, deveria produzir, criar no espaço da escola o seu espaço de criação, desenvolver o seu processo poético e fazer participar os estudantes dessa escola. No entanto, considero que, em função da nossa especificidade, coloco a arte à frente da docência e uno as palavras em uma só."

2 Para Paulo Freire (1996, p. 24), "aprender precedeu o ensinar ou, em outras palavras, ensinar se diluía na experiência realmente fundante de aprender." A partir disso e do pensamento de Carmen Lúcia Pérez e Carmen Sanches Sampaio (2012), uso aprenderensinar juntos.

3 Marie-Madeleine Béziers desenvolveu seus estudos inicialmente com Suzanne Piret, com quem publicou o livro A Coordenação Motora, e seguiu pesquisando, depois da morte de Piret (1997), com Yva Hunsinger, com quem publicou O bebê e a coordenação motora (MENDONÇA, 2000). manais, em duas turmas, em 2014 e 2015, no Curso de Licenciatura em Dança da Universidade Estadual do Sudoeste da Bahia (UESB). Criado em 2010, o curso passou por reforma curricular em 2012 - quando o projeto político pedagógico foi calcado no tripé: artista-docente-pesquisador ${ }^{4}$. Nos dois primeiros semestres, as disciplinas são compartilhadas com o Curso de Licenciatura em Teatro, inclusive as duas primeiras montagens de espetáculo. Há outros dois componentes específicos de montagem em dança.

A presente pesquisa se utilizou de metodologia mista: autobiografia (FINGER; NÓVOA, 2010; PASSEGI; ABRAHÃO, 2012) e somático-performativa (FERNANDES, 2014; FERNANDES, 2012). Por isso, o uso de diários da pesquisadora e dos alunos e alunas se fez essencial na pesquisa, cujas reflexões partem destas escritas.

\section{Abordagens somáticas}

O campo da Educação Somática surgiu no início do século passado, com a criação de técnicas e métodos somáticos, sendo constituído como tal nos anos 1970, por Thomas Hanna. Desde o seu surgimento, passou por diversas fases, se manifestando, nos últimos anos, pelo hibridismo de técnicas e métodos e a apropriação de procedimentos por diversas áreas, entre elas, a dança. Desta forma:

O que hoje chamamos de somática, e que,
muitas vezes, é utilizado nos contextos
mais variados e imprevisíveis possíveis, ori-
ginou-se de técnicas específicas altamen-
te estruturadas em termos de princípios,
procedimentos, treinamentos e aplicações.
Essas técnicas não apenas têm premissas
semelhantes, mas pertencem a arcabou-
ços complexos diferenciados, inovadores e
relevantes de atuação e formação que de-
mandam tempo e dedicação. Portanto, não
podem nem devem ser subestimadas ou ge-

4Apesar de o PPC apontar para este tripé, considero que tanto o(a) artista quanto o(a) docente são pesquisadores(as), na concepção de Contreras e Perez de Lara (2010), que entendem a investigação como experiência, que passa pela reflexão na ação. Por isso, e pela concepção de artistadocnete antes elencada, optei por este termo e não o do tripé. 
neralizadas em prol da simples utilização de suas linhas gerais. Assim, podemos inferir que toda técnica de Educação Somática tem uma Abordagem Somática, mas nem toda Abordagem Somática está vinculada a alguma técnica de Educação Somática, apesar de que isso seria altamente recomendado e coerente. (FERNANDES, 2015, p. 16).

Neste sentido, o Sistema Laban/Bartenieff e a Coordenação Motora são considerados, nesta pesquisa, abordagens somáticas.

De acordo com Hanna (1977), são características da educação somática: a autorregulação, autocorreção, a automelhoria e autoconsciência. Além destas, diversos(as) autores(as) apontam outras marcas comuns ao campo. A partir de Bolsanello (2005), Domenici (2010), Fortin (1999, 2011), Hanna (1986/88), Lima (2010) e Strazzacappa (2009a, 2009b e 2012), pode-se elencar os seguintes princípios somáticos:

Privilégio à informação que vem do corpo
Descoberta pessoal
Autorregulação
Reconhecimento de padrões
Corpo saudável
Mudança de ritmo
Integração

\section{— Pensamentos somáticos em Laban e Béziers}

O que atualmente chamamos de Análise Laban/Bartenieff de Movimento (LMA, na sigla em inglês) ou Sistema Laban/Bartenieff é uma série de desenvolvimentos posteriores aos realizados por Laban no início do século passado, com o acréscimo das categorias Corpo e Forma às iniciais Esforço (Expressividade ${ }^{5}$ ) e Espaço. Para Laban (1978), o ser humano precisa de equilíbrio em seu movimento. É por isso que, na sua avaliação, era importante que cada pessoa aprendesse a usar de forma consciente os fatores do movimento (Categoria Expressividade), tanto como prevenção quanto como terapia. Segundo ele, "há duas causas fundamentais que obstruem um fácil domínio do movimento: inibições de ordem física e de ordem mental" (LABAN, 1978, p. 194). Ele afirmava ainda que a estrutura anatômica das pessoas the conferiria uma tendência de movimento e seria afetada também por qualidades emocionais e mentais. É possível verificar, apesar de não estar explicitada, a integração corpomente: Laban "em todos os seus escritos deixa claro que quando emprega a palavra 'corpo' ou 'corporal', está querendo significar 'todos' os aspectos do corpo" (RENGEL, 2006, p. 126).

Ao compreender que o indivíduo deve aprender a se mover de forma consciente e que existem tendências naturais de cada pessoa, o Sistema Laban/ Bartenieff também nos informa que há necessidade do reconhecimento dos padrões. Acrescenta-se a isso que Laban dizia que: "toda pessoa tem a tendência de ampliar a gama de suas capacidades de esforço, sendo que essa ampliação se relaciona ao seu próprio desenvolvimento pessoal" (LABAN, 1978, p. 166). Suquet (2011) elucida como isso se daria: segundo ela, para Laban, o bailarino, ator ou mímico deveria desenvolver um saber sentir, que vai além dos fatores biológicos. "O afinamento da percepção deve também conectar o bailarino aos fluxos rítmicos da vida moderna, a suas vibrações" (SUQUET, 2011,

5 Em O corpo em movimento, Fernandes (2006) denomina a categoria Esforço como Expressividade. No artigo Sobre corpos vivos (FERNANDES, 2016, p. 61), a autora afirma que: "Para fundamentar a categoria da Eukinética, Laban escolheu o termo em alemão Antrieb, que significa ímpeto ou propulsão". Diz a autora ainda (FERNANDES, 2016, p. 65-66) que: "Apesar de expressividade ser um termo que, na minha experiência, mantém-se fiel à noção de uma 'atitude mais interna com relação aos quatro fatores', ainda não me parece o termo mais próximo a ímpeto ou propulsão [...] Portanto, recentemente, tenho traduzido Antrieb para 'pulsão'. [...]". 
p. 525). De acordo com a autora, o modo como Laban abordava a improvisação fazia do esquecimento "[...] (dos saberes adquiridos, dos automatismos...) a condição sine qua non tanto de toda rememoração quanto de toda criação" (SUQUET, 2011, p. 526).

Outro princípio somático do Sistema Laban/ Bartenieff é o privilégio à informação do corpo. "Ele, já na sua época, dizia que não é possível separar conceitos abstratos, ideias e/ou pensamentos, da experiência corporal" (RENGEL, 2006, p. 122). Com o desenvolvimento do Sistema Laban/Bartenieff, a partir dos Bartenieff Fundamentals $\AA$ (BFs), esse princípio pode ser mais bem compreendido, por exemplo, quando acionamos nossas conexões ósseas para a realização de um movimento como o arabesque, provocando a chamada intenção espacial.

Quando comecei a utilizar o Sistema Laban/Bartenieff ${ }^{6} \mathrm{em}$ minhas aulas de balé clássico, interessavame pesquisar os movimentos com as variações dinâmicas e ver o que mudava na expressão. Para um(a) dançarino(a), por exemplo, identificar esta gama de variedades de movimento - e como ele(a) preferencialmente se move - é riquíssimo para a expansão da sua expressividade. Aos poucos, descobri que a Categoria Expressividade também podia me ajudar a pesquisar os movimentos codificados do balé clássico e chegar à sua forma espacial.

Junto com a Categoria Expressividade do Sistema Laban/Bartenieff e seus princípios somáticos, tenho utilizado a Coordenação Motora ${ }^{7}$, da fisioterapeuta Marie-Madeleine Béziers, que realizou suas pesquisas em parceria com Yva Hunsinger e Suzanne Piret. "As autoras desenvolveram, ao

6 As pesquisas iniciais começaram em 2007, durante a graduação em Dança, se estenderam no Mestrado e Doutorado. Atualmente, finalizando a formação em Sistema Laban/Bartenieff da Faculdade Angel Vianna, tenho estudado também a Categoria Corpo, com o uso dos BFs nas aulas de balé clássico.

7 Abordagem conhecida durante a graduação em Dança, entre 2005-2009 e pesquisada desde então. Atualmente, existe uma formação específica no Brasil, que não havia na época. Não realizei a mesma ainda, mas fiz formação - em fase final - de Análise Funcional na Prática do Balé, com Zélia Monteiro, que estudou com Béziers. longo de sua trajetória profissional, um profundo e complexo estudo sobre a motricidade humana e suas origens no desenvolvimento do bebê" (TRINDADE, 2007, p. 107). Na Coordenação Motora, proposta por elas, nosso corpo se organiza em unidades de coordenação e há um movimento espiralado de nossos ossos que provocam torções - entre um elemento e outro, que produz os direcionamentos - e seus alinhamentos ou desalinhamentos: segundo Béziers e Hunsinger (1994), o princípio mecânico da coordenação motora se manifesta pelos movimentos de enrolamento, endireitamento, torção e tensão, que ocorrem nas três dimensões no espaço, sendo o enrolamento/endireitamento o movimento de base.

Apesar de a Coordenação Motora não estar elencada nem no International Somatic Movement Education \& Therapy (ISMETA ${ }^{8}$ ), dos Estados Unidos, nem no Regroupement pour L'education Somatique (RES ${ }^{9}$ ), do Canadá, tem sido entendida, no Brasil, como uma abordagem somática (BIANCHI; NUNES, 2015; MONTEIRO, 2011; STORTO, 2005). Na França, origem do desenvolvimento da mesma, existe a Association Accord Cinétique, composta por pessoas formadas na Analyse Fonctionnelle du Corps dans le Mouvement Dansé (AFCMD), criada por Hubert Godard e Odile Rouquet. A AFCMD é equivalente à Educação Somática na dança, naquele país, e se alimenta da obra de teóricos do movimento, como Dalcroze, Delsarte e Laban, bem como de práticas desenvolvidas por Alexander, Bartenieff, Cohen, Feldenkrais e Todd; assim como está em consonância com os trabalhos de "[...] Piret e Béziers, de Godelieve Denys Struyf e outros que contribuíram para o surgimento da noção de cadeias musculares" (AFCMD, s.d, s.n.).

8 Trata-se de uma associação estadunidense de indivíduos e instituições que trabalham com o movimento somático a partir da educação ou da terapia. Fazem parte da Ismeta a Alexander Technique International, a Body-Mind Centering Association e a Feldenkrais Guild of North America.

9 Associação canadense que abriga pessoas formadas nos métodos e técnicas somáticos: Feldenkrais, Alexander, Ginástica Holística e Movimento Consciente, prioritariamente, além de Somaritmos, BMC e Continuum. 
Do mesmo modo que outras abordagens somáticas, a questão do reestabelecimento da saúde também aparece na Coordenação Motora:

A gênese da Coordenação Motora está no restabelecimento ou na manutenção, da saúde do corpo. [...]. E que se dá a partir de [...] uma experiência pessoal, apoiada na própria estrutura corporal, no espaço-tempo, em relação com o mundo, favorecendo a instauração de estados mais perceptíveis e mais atentos. (BIANCHI; NUNES, 2015, p. 164, grifo das autoras).

Para suas criadoras, o corpo era considerado corpo vivenciado, sem a ruptura de corpo e espírito. A partir da Coordenação Motora, pode-se "[...] compreender o movimento como um todo organizado, capaz de situar-se paralelamente ao psiquismo, com ele e perante ele. Então um poderá ser estudado em função do outro" (BÉZIERS; PIRET, 1992, p. 13).

As fisioterapeutas francesas propunham que a reeducação corporal passasse pelo toque, que indicava o direcionamento ósseo ao paciente. Mas, "na prática, Béziers insistia na educação do olhar" (STORTO, 2005, p. 56). O sujeito (re)aprendia a olhar-se, mesmo que isso partisse, inicialmente, do toque do(a) fisioterapeuta.

Não há nos estudos de Béziers e suas colaboradoras nenhuma indicação clara sobre a questão da mudança de ritmo - outro princípio somático. "A Coordenação Motora propõe que se experiencie o mesmo gesto em diferentes planos e em diferentes relações com o espaço, para ser possível perceber a mudança na forma desse gesto" (BIANCHI; NUNES, 2015, p. 160). Ao realizar o movimento de diversas maneiras, a pessoa estará, em alguma delas, variando o tempo ou ritmo.

Em minhas aulas, utilizo a lentidão para que os(as) alunos(as) percebam a dinâmica do gesto coordenado e, aos poucos, possam acelerar sem que desconstruam o alinhamento conquistado. Assim, a Coordenação Motora aparece como estudos anatômicos em movimento: o(a) estudante reconhece sua estrutura ósseo-muscular, depois pesquisa mo- vimentos para chegar ao princípio da torção/tensão. É com base nele que trabalhamos os desenhos corporais específicos, os direcionamentos ósseos em torções para que cheguemos ao alinhamento.

\section{Princípios e procedimentos} somáticos nas aulas

Apesar de vir desenvolvendo a proposta metodológica aqui apresentada, ao longo de anos, somente no Doutorado a mesma foi sistematizada, em duas turmas de quinto semestre de Técnica do Corpo II - Princípios da Dança Clássica, em 2014 e 2015. Em minha pesquisa, a turma de 2014 tinha nove alunas e a de 2015, oito estudantes - sendo um homem. Em ambas, o conhecimento anterior em balé clássico era de 1/3 dos(as) estudantes. Trata-se da única disciplina dedicada a esta técnica corporal.

Apesar de o projeto pedagógico prever a formação do artista-docente-pesquisador, a pesquisa em arte era desenvolvida em disciplinas de montagem e criação. As ementas das denominadas Técnica do Corpo - Moderna, Clássica, Pós-Moderna e Contemporânea, respectivamente - não previam investigações artísticas. No entanto, desde que comecei a minha investigação - ainda de forma empírica nos anos 1990 e de maneira sistematizada no Mestrado e o Doutorado - sobre aprenderensinar balé clássico, a expressividade e a criação em dança se faziam presentes, reforçando o meu entendimento de não dissociar artistadocente.

Ao longo dos anos, a partir das abordagens da Coordenação Motora e do Sistema Laban/Bartenieff, percebi que minhas aulas se estruturam, do ponto de vista de conteúdos, na tríade: dança ${ }^{10}$-expressividade-estrutura corporal, e do ponto de vista metodológico, nos eixos: (re)conhecer, (re)significar, conceituar e explorar. A partir do pensamento somático, tudo está integrado, conteúdos e eixos metodológicos. Assim, os conteúdos da tríade são trabalhados aos pares, como por exemplo, ao

10 Aqui me refiro aos conteúdos do código da dança, que no caso do balé são os seus movimentos codificados. 
enfocar a unidade de coordenação ísquio-calcâneo, dou ênfase a movimentos codificados do balé clássico que se utilizem desta unidade. Do mesmo modo, os eixos metodológicos são trabalhados em espiral, um levando ao outro. Por isso, tenho denominado a proposta metodológica como Espiral do/no movimento/conhecimento. Os eixos metodológicos têm os seguintes procedimentos:

- Fechar os olhos durante a movimentação;

Iniciar o movimento a partir de um direcionamento ósseo;

- Observar o(a) outro;

Escrever diário, inventário e carta (escrita reflexiva);

- Começar a sequência de movimento pelo lado esquerdo;

- Explorar verbos;

Realizar torções;

Variar a dinâmica.

O uso dos olhos fechados é comum em várias práticas somáticas e é proposto para que a pessoa não busque um feedback externo, permitindo-lhe se autoperceber, pois como afirma Gillain (2008), os estímulos externos diminuem a nossa capacidade de atenção e esta é a chave para estarmos no presente. No eixo metodológico explorar - quando estamos, por exemplo, pesquisando um movimento - peço que fechem os olhos para que se atentem ao que estão fazendo. Do mesmo modo, posso solicitar que realizem uma sequência inteira de olhos fechados. Fechar os olhos possibilita que a pessoa perceba sensações e o caminho do movimento, ou seja, tem relação também com o eixo (re)conhecer.

Para uma das alunas, fechar os olhos a deixa livre para executar o movimento, sem um modelo a seguir. Ela escreveu em seu diário que os olhos fechados Ihe fazem "[...] refletir como cheguei naquele resultado, o que me faz pensar como chegar naquela sequência." Ou seja, ela dá atenção ao caminho do movimento. Para uma futura artistadocente, compreender a iniciação e sequenciamento de um movimento (princípio do Sistema Laban/Bartenieff) vai lhe permitir ensiná-lo e, ao mesmo tempo, ao utilizar o direcionamento ósseo, as alavancas e/ou a musculatura adequada, terá economia de esforço.

Outro procedimento é realizar o movimento a partir de um osso, por exemplo: como iniciar um ten$d u$ pelo ísquio e fazer o mesmo movimento pelo calcâneo? O que muda na realização deste movimento? No Sistema Laban/Bartenieff este procedimento está relacionado ao princípio Iniciação e Sequenciamento do Movimento, em que: "uma mesma ação pode ser realizada de maneiras totalmente distintas, dependendo de qual parte inicia e qual(is) parte(s) dá(dão) continuidade ao movimento" (FERNANDES, 2006, p. 67). Em minhas aulas, esse procedimento pode aparecer nas sequências prontas - e está relacionado aos eixos (re)conhecer e explorar. Para algumas alunas, pensar no movimento a partir da estrutura anatômica faz com que o movimento ganhe mais sentido; enquanto outras acreditam que aumenta a concentração. Em uma de suas reflexões, uma aluna escreveu: "realizar os exercícios pensando na estrutura anatômica é importante porque facilita a compreensão, entendemos o que está sendo trabalhado e como está sendo; e os resultados."

Esse mesmo procedimento - do movimento a partir do osso - também é usado nos laboratórios de criação, quando os(as) estudantes criam células coreográficas. As criações podem ser pensadas como sistematização do conhecimento - eixo conceituar - ou (re)significações. Aprender a criar e desenvolver estratégias para criação é um conhecimento que artistasdocentes devem construir ao longo de suas formações.

Além disso, o momento específico de criação não usual no ensino de técnicas codificadas - permite ao(à) estudante a formação em processos criativos, vivenciar formas diferentes de criar sequências coreográficas, sistematizar o que aprendeu e compreender a técnica como possibilidade criativa. Uma das estudantes escreveu em seu diário: "[...] as aulas não são apenas técnicas, vão além das técnicas, porque entendemos os movimentos e 
pesquisamos outras formas de movimentos, partindo dos movimentos codificados. Esses novos elementos são percebidos ao estudarmos, pesquisarmos e criarmos as células para as sequências. Essa junção técnica e criação é muito positiva e prazerosa." Estes momentos permitem que não haja separação entre técnica e expressão, assim como entre artista e docente. Neste sentido, concordo com Cardona quando diz que: "ao separar artificialmente o que está unido - técnica e criação - os coreógrafos e os professores propiciam consequências graves. No caso dos jovens, posso afirmar que não há uma formação artística [...]" (CARDONA, 2012, p. 58).

A observação do(a) colega é outro procedimento comum nas minhas aulas. De acordo com Mead (2012), o feedback do(a) colega é mais efetivo que se o(a) aluno(a) olhasse o(a) professor(a) fazer a sequência, pois tende a ficar mais confortável com seu(sua) colega. Geralmente solicito que observem os(as) colegas no desenvolvimento de sequências, em duplas ou em grupo. Segundo Hand (2012), a partilha e a reflexão sobre o movimento dão origem a insights e percepções novas. Acredito que observar o(a) outro(a) permite a emergência de um conhecimento essencial para artistasdocentes, a 'afinação' do olhar.

A escrita reflexiva - a partir de diários, inventários ou cartas - é outro procedimento utilizado. Convido os(as) estudantes a terem um diário no qual anotam sensações, percepções, descobertas e dúvidas sobre o processo. Toda vez que os leio, devolvo-Ihes com uma carta e, ao final do processo, sugiro que escrevam uma carta a alguém, apresentando o diário. Essas anotações têm duplo uso: "[...] para si mesmo, como forma de assimilação e retenção do que foi vivido em cada encontro, e uso pelo outro - no caso, pela pesquisa e por seus possíveis leitores [...]" (FORTUNA, 2012, p. 188). Quando proponho essas diversas escritas, estou tentando fazer com que minhas alunas e alunos acessem questões para além da mecânica do movimento, que consigam perceber em si aspectos que podem estar influenciando na coordenação de seus movimentos e em seus alinhamentos ou aspectos que influenciem na aprendizagem das movimentações. A escrita reflexiva, em suas diferentes versões, vai ao encontro do que Contreras (2002, p. 107) vem discutindo, de que "[...] o conhecimento não precede a ação, mas sim está na ação. [...] Por isso é um conhecimento na ação" (grifo do autor), e de que não há separação entre o pensar e o fazer, propondo que façamos reflexão-na-ação. Este tipo de atitude permite, na avaliação do autor, a emergência do professor-pesquisador. Em um curso de Dança, que trabalha tanto as dimensões artísticas quanto pedagógicas, a reflexão-na-ação irá ajudar na constituição do professor-pesquisador-artista, como proposto no projeto pedagógico da Uesb.

Outro procedimento é começar a sequência pelo lado esquerdo ou o lado menos usual, pois provoca "desequilíbrios" - entendidos no sentido piagetiano ${ }^{11}$, ou seja, como "[...] fontes de progresso no desenvolvimento dos conhecimentos, já que obrigam o sujeito a superar seu estado" (GARCÍA; FABREGAT, 1998, p. 88-89). Neste caso, estou desafiando os(as) estudantes a resolverem uma questão: como começar pelo outro lado? É um descondicionamento somático, geralmente usado nos eixos da (re) significação ou do (re)conhecimento. Do ponto de vista formativo, trata-se de uma experiência que tem relação com o uso dos olhos fechados e a iniciação pelo direcionamento ósseo, ou seja, que provoca a busca de soluções para 'o problema', auxiliando também no desenvolvimento da criatividade.

No eixo explorar, o procedimento mais utilizado é o da pesquisa a partir dos verbos essenciais do balé clássico: dobrar, estender, lançar, deslizar, girar, saltar e elevar. De acordo com Yuzurihara (2012), mais de $70 \%$ dos movimentos codificados do balé clássico derivam de verbos e muitos deles dão pistas do que são os movimentos. A exploração dos verbos está diretamente relacionada ao pensamento de Laban: "em vez de estudar cada movimento particular, pode-se compreender e praticar o princípio do mo-

11 Piaget (1970, 1987, 2002 e 2011) dizia que a construção do conhecimento se dava no jogo de equilíbrio e desequilíbrio constantes. 
vimento" (LABAN, 1990, p. 16). Pesquisar os movimentos do balé clássico a partir de verbos significa partir de um princípio para chegar a um código. Assim, posso explorar o dobrar, compreendê-lo cinestesicamente, para chegar ao conceito de plié.

Outros dois procedimentos realizados têm relação com as abordagens da Coordenação Motora e do Sistema Laban/Bartenieff: realização de torções e variação da dinâmica do movimento. Como dito anteriormente, na Coordenação Motora, nosso alinhamento se dá a partir de direcionamentos opostos das unidades de coordenação, que realizam torções. Começo a exploração das torções das unidades pelo entendimento do verbo torcer, para posteriormente pesquisar as torções dos direcionamentos ósseos. Acredito que conhecer como se dá a estrutura musculoesquelética ajuda no reconhecimento de padrões de movimento e a reaprender a se movimentar, entendendo seus limites. Sobre esta aprendizagem, um aluna escreveu: "nas minhas antigas escolas de ballet eu nunca tinha passado por um trabalho tão profundo sobre o meu corpo, agora tenho aprendido mais a respeitar meus limites e entender que a funcionalidade de cada parte do corpo." Não é comum em aulas de balé esta aprendizagem e, nas graduações em Dança, quando não existem componentes curriculares relacionados à Educação Somática, geralmente este conteúdo se dá de forma teórica, em aulas de Anatomia ou Cinesiologia. Em Técnica do Corpo II, as futuras artistasdocentes estavam experienciando este corpo vivenciado e aprendendo na prática.

Por outro lado, a variação das dinâmicas também nasce da exploração e do entendimento de cada fator de movimento. A partir da compreensão de cada fator, vamos explorá-los nos movimentos de balé clássico: como acelerar um movimento tipicamente lento? O que isso provoca? Do mesmo modo que posso chegar ao código do balé clássico a partir da exploração dos fatores: por exemplo, para o chassé pesquiso o deslizar das ações básicas de esforço.

Para uma das minhas alunas, realizar a movimentação variando as qualidades lhe per- mitiu pensar na intenção e não apenas na sequência, não somente na ordem em que os movimentos ocorrem. Isso é importante, pois:

O uso consciente da categoria expressividade na classe impacta positivamente no desenvolvimento técnico e artístico. Artisticamente, experimentando as dinâmicas, os dançarinos aprendem como usar sua energia especificamente e variadamente, a fim de criar diferentes modos e qualidades ao dançar. (WHITTIER, 2013, p. 403).

Segundo ela, há várias maneiras de se fazer os movimentos de balé clássico e que com LMA os(as) alunos(as) podem experimentar múltiplas possibilidades, pois: "este processo ensina-os a interpretar e 'colorir' os passos de uma forma pessoal, com a qual desenvolvem singularidades pessoais e artísticas" (WHITTIER, 2013, p. 404). Para a autora, aprender os movimentos, desta forma, torna o processo criativo, em que os(as) alunos(as) são desafiados a explorar as possibilidades do movimento. Além disso, se os(as) estudantes são formados(as) na perspectiva de que contribuem para o processo de aprendizagem, "[...] estarão mais aptos a participar criticamente e criativamente no seu próprio desenvolvimento" (WHITTIER, 2006, p. 132). Na formação do(a) artistadocente, isso é relevante, pois ao mesmo tempo em que descobre que um movimento pode ser feito de várias formas, aprende a dar nuances à movimentação e desenvolve a sua autonomia.

\section{Conclusões}

A partir das escritas dos(as) alunos(as), percebi que a anatomia em movimento - baseada na Coordenação Motora - ajuda na compreensão do alinhamento esquelético-muscular, impactando na economia de esforço, no entendimento da iniciação e sequenciamento do movimento, como também a compreender os movimentos do balé clássico, dando outras significações e expressões a estes; e auxilia a pessoa a perceber-se. 0 mesmo se passa com a abordagem do Sistema 
Laban/Bartenieff, que facilita a compreensão do código e sua (re)significação, proporcionando ganho de autonomia e de expressividade. Nesta proposição, o(a) aluno(a) aprende a se autoperceber e isso vai ajudá-lo(a) a se autoformar. Uma autopercepção e formação que se dão para além das instâncias do código da dança clássica, mas também para suas constituições como artistasdocentes. Uma estudante escreveu que o processo permite dar "[...] a possibilidade de criarem e experimentarem seus corpos, não sendo totalmente marionetes, mas bailarinos autônomos."

Do mesmo modo, o processo mostrou que é possível construir conceitos de movimentos do balé clássico e criar neologismos. $E$, isso, para a dança como um todo, é muito importante: um(a) artistadocente se dar conta das possibilidades de construções a partir de uma técnica codificada e de perceber como esta técnica é desconstruída e reconstruída, ressignificada.

Outra questão apontada pelos(as) estudantes é que as abordagens somáticas facilitaram a aprendizagem do balé clássico. Isso pode significar que outras técnicas de dança podem ser aprendidas a partir dessas abordagens com bons resultados. Pelo que vivi, as abordagens somáticas permitem a compreensão de processos e resultados; afinam o olhar para o movimento; possibilitam o surgimento de novas percepções, de busca de alternativas e acabam por expandir a criatividade. Do mesmo modo, que trazem benefícios para além da técnica de dança trabalhada, ajudando na compreensão de si, de forma globalizada. A vivência com princípios e abordagens somáticas possibilitou ainda a emergência do pesquisador-professor-artista e, acredito, ao passarem por uma aprendizagem diferenciada de uma técnica codificada, esses(as) futuros(as) artistasdocentes podem repensar tantos seus fazeres artísticos quanto docentes, contribuindo para mudanças metodológicas na dança.

\section{ANALYSE FONCTIIONNELE DU CORPS} DANS LE MOUVEMENT DANSÉ. Qui sommesnous. Pantin, France. S.d. Disponível em : http://afcmd.com/. Acesso em: 25 jul. 2018.

BALDI, Neila Cristina. A educação somática na formação de artistas docentes de dança. In: INSTITUTO FESTIVAL DE DANÇA DE JOINVILLE; ROCHA, Thereza. (Orgs.). Graduações em dança no Brasil: o que será que será? Joinville: Nova Letra, 2016.

BÉZIERS, Marie-Madeleine; PIRET, Suzzane. A coordenação motora: aspecto mecânico da organização psicomotora do homem. $3^{a}$ ed. São Paulo: Summus Editorial, 1992.

BÉZIERS, Marie-Madeleine; HUNSINGER, Yva. O bebê e a coordenação motora: os gestos apropriados para lidar com a criança. 4ª ed. São Paulo: Summus Editorial, 1994.

BIANCHI, Paloma. NUNES, Sandra Meyer. A coordenação motora como dispositivo para criação: uma abordagem somática na dança contemporânea. Revista Brasileira de Estudos da Presença, Porto Alegre, v. 5, n.1, p. 148-168. Jan/abr. 2015.

BOLSANELLO, Débora. Educação somática: o corpo enquanto experiência. Motriz, Rio Claro, v.11, n.2, p.99-106, mai./ago. 2005.

CARDONA, Patricia. La poetica de la enseñanza. México: INBA/Centro Nacional de Investigación, 2012.

CONTRERAS, José. A autonomia de professores. São Paulo: Cortez, 2002.

CONTRERAS, José; PÉREZDE LARA, Núria. La experiencia y la investigación educativa. In: CONTRERAS, José; PÉREZ DE LARA, Núria. (Coord.). Investigar la experiencia educativa. Madrid: Morata, 2010. p. 21-86. 
DOMENICl, Eloisa. O encontro entre dança e educação somática como uma interface de questionamento epistemológico sobreas teorias do corpo. Pro-Posições, Campinas, v. 21, n. 2 (62), p. 69-85, maio/ago. 2010.

FERNANDES, Ciane. O corpo em movimento: o sistema Laban/Bartenieff na formação e na pesquisa em artes cênicas. 2a Ed. São Paulo: Annablume, 2006.

FERNANDES, Ciane. Movimento e Memória: Manifesto da Pesquisa Somático-Performativa. In: Anais do X Congresso da Associação Brasileira de Pesquisa e Pós-graduação em Artes Cênicas. Porto Alegre: UFRGS, 2012.

Pesquisa somático-performativa: sintonia, sensibilidade, integração. Art Research Journal. Brasil, Vol. 1-2, p. 76-95, jul./dez. 2014.

Quando o Todo é mais que a Soma das Partes: somática como campo epistemológico contemporâneo. Rev. Bras. Estud. Presença, Porto Alegre, v. 5, n. 1, p. 9-38, jan./abr. 2015. Disponível em: <http://www. seer.ufrgs.br/presenca> Acesso em: 21 abr. 2015.

Sobre corpos vivos: pulsões de uma autenticidade em movimento. Encontro Teatro. Goiânia, n. 3, p. 55-76, jul. 2016.

FINGER, Mathias; NÓVOA, Antonio. O método (auto) biográfico e a formação. São Paulo e Natal: Paulus e EDUFRN, 2010. p. 155-187.

FORTIN, Sylvie. Educação somática: novo ingrediente na formação prática em dança. Cadernos do GIPE-CIT, Salvador, n. 2, p. 40-55, fev. 1999.

Nem do lado direito, nem do lado avesso: o artista e suas modalidades de experiência de si e do mundo. In: WOSNIAK, Cristiane. MARINHO, Nirvana. O avesso do avesso do corpo - educação somática como práxis. Seminários de dança 4. Joinville: Nova Letra, 2011. p. 27-42.
FORTUNA, Tânia Ramos. Ludobiografia: uma invenção metodológica em pesquisa (auto)biográfica em educação. In: PASSEGI, Maria da Conceição; ABRAHÃO, Maria Helena Menna Barreto. (Orgs.). Dimensões epistemológicas e metodológicas da pesquisa (auto) biográfica: Tomo II. Natal: EDUFRN; Porto Alegre: EDIPUCRS; Salvador: EDUNEB, 2012, p.165-202.

FREIRE, Paulo. Pedagogia da Autonomia: saberes necessários à prática educativa. São Paulo: Paz e Terra, 1996.

GARCÍA, Antonio; FABREGAT, Artemio. A construção humana através da equilibração de estruturas cognitivas: Jean Piaget. In: MINGUET, Pilar Aznar. (Org). A construção do conhecimento na educação. Porto Alegre: ArtMed, 1998. p. 81-109.

GILLAIN, Vandana Claire. L'education somatique et l'apprentissage scolaire. Le Regroupement pour l'éducation somatique, 2008. Disponível em: http:// education-somatique.ca/. Acesso em: 04 mar. 2014.

HAND, Jacqueline F. Within and beyond the body: the perception of energy. Repertório, Salvador, $\mathrm{n}^{\circ}$ 18, p.103-112, 2012.1.

HANNA, Thomas. The somatic healers and the somatic educator. SOMATICS: Magazine-Journal of the Bodily Arts and Sciences, Volume I, No. 3, Autumn 1977. Disponível em: http://somatics.org/library/ htl-somatichealed.html. Acesso em 02 fev.2014.

What is somatics? Somatics: Magazine-Journal of the Bodily Arts and Sciences, local, V. 4-6, p. 1986/88. Disponível em: http://somatics. org/library/htl-wis4.html. Acesso em 06 out. 2013.

ICLE, Gilberto. "O que é pedagogia da Arte?" In: ICLE, Gilberto. Pedagogia da arte: entre-lugares da escola. Volume 2. Porto Alegre: Editora da UFRGS, 2012, p.11-22. 
LABAN, Rudolf. Domínio do movimento. São Paulo: Summus editorial, 1978.

Dança educativa moderna. São Paulo; Ícone Editora, 1990.

LIMA, José Antônio. Educação somática: diálogos entre educação, saúde e arte no contexto da proposta da Reorganização Postural Dinâmica. 2010. 184 fls. Tese (Doutorado em Educação) - Faculdade de Educação, Universidade Estadual de Campinas, Campinas, 2010.

MEAD, David. Developing the expressive artist: Constructive creativity in the technique class. In: STINSON, Susan; NIELSEN, Charlotte Svendler; LIU, Shu-Ying Liu (Eds). Dance, young people and change: Proceedings of the daCi and WDA Global Dance Summit. Taiwan: Taipei National University of the Arts, 2012. Disponível em: http://www.ausdance.org/. Acesso em: 9 fev. 2016.

MENDONÇA, Maria Emília. Ginástica Holística: história e desenvolvimento de um método de cuidados corporais. São Paulo: Summus Editorial, 2000.

\section{MINISTÉRIO DA EDUCAÇÃO. Sistema} E-MEC. Brasília, 2020. Disponível em: https:// emec.mec.gov.br/. Acesso em: 10 ago. 2020.

MONTEIRO, Zélia. A influência do trabalho de Madame Béziers no ensino do balé. In: WOSNIAK, Cristiane. MARINHO, Nirvana. O avesso do avesso do corpo - educação somática como práxis. Seminários de dança 4. Joinville: Nova Letra, 2011. p.93-96.

PASSEGI, Maria da Conceição; ABRAHÃO, Maria Helena Menna Barreto. (Orgs.). Dimensões epistemológicas e metodológicas da pesquisa (auto)biográfica: Tomo I. Natal: EDUFRN; Porto Alegre: EDIPUCRS; Salvador: EDUNEB, 2012.
PÉREZ, Carmen Lúcia Vidal; SAMPAIO, Carmen Sanches. Conversas sobre aprenderensinar a ler a escrever: (nos) alfabetizando com crianças e sem cartilhas... In: LIBÂNEO, José Carlos; ALVES, Nilda. (Orgs.). Temas de Pedagogia: diálogos entre didática e currículo. São Paulo: Cortez, 2012. p.395-429.

PIAGET, Jean. A construção do real na criança. Rio de Janeiro: Zahar, 1970.

A formação do símbolo na criança: imitação, jogo e sonho, imagem e representação. Rio de Janeiro: Zahar, 1971.

O nascimento da inteligência na criança. $4^{a}$ Ed. Rio de Janeiro: LTC (Livros Técnicos e Científicos Editora Ltda), 1987. Fontes, 2002.

Epistemologia genética. São Paulo: Martins

RENGEL, Lenira. Fundamentos para análise do movimento expressivo. In: MOMMENSOHN, Maria; PETRELLA, Paulo. (Orgs.). Reflexões sobre Laban, o mestre do movimento. São Paulo: Summus editorial, 2006.

STORTO, Juliana Nogueira. Coordenação motora. In: RIBEIRO, Ana Rita; SOUZA, Fátima Andrade; MAGALHÃES, Romero. (Orgs.). Catálogo de Abordagens terapêuticas. São Paulo: Casa do Psicólogo, 2005. p. 55-58.

STRAZZACAPPA, Márcia. Educação somática: princípios e possíveis desdobramentos. Repertório - Teatro e Dança, Salvador, ano 12, número 13, p. 48-54, 2009.2 (a).

As técnicas de educação somática. In: BOLSANELLO, Débora Pereira. (Org). Em pleno corpo - educação somática, movimento e saúde. Curitiba: Juruá Psicologia, 2009b. p. 309-318. 
Educação somática e artes cênicas: princípios e aplicações. Campinas: Papirus, 2012.

SUQUET, Annie. Corpo dançante: um laboratório da percepção. In: CORBIN, Alain; COURTINE, Jean-Jacques. VIGARELLO, Georges. História do corpo: as mutações do olhar. O século XX. Petrópolis: Vozes, 2011.

TRINDADE, André. Gestos de cuidado, gestos de amor: orientações sobre o desenvolvimento do bebê. São Paulo: Summus, 2007.

WHITTIER, Cadence. Laban Movement Analysis Approach to Classical Ballet Pedagogy. Journal of Dance Education. Silver Spring: National Dance Education Organization, V. 6, N. 4, 2006. p.124-132. Disponível em: http://www.tandfonline. com/doi/abs/10.1080/15290824.2006.10387325?journalCode=ujod20. Acesso em: 8 fev. 2016 .

Transforming Tradition: The Integration of Laban Movement Analysis and Classical Ballet. In: SOCIETY OF DANCE HISTORY SCHOLARS/ NORDIC FORUM FOR DANCE RESEARCH (SDHS/NOFOD), 2013. Disponível em: https://sdhs.org/proceedings/2013/pdf-old/Whittier_81.pdf. Acesso em: 01 mar. 2014.

YUZURIHARA, Akiko. The construction of classical dance vocabulary in the light of the principle of variation: a comparison with the compositional techniques of contemporary dance. Comparative Theater Review. Tóquio: Japanese Society for Theatre Research, Vol.12, N.1, Mar 2013, p. 133-145. Disponível em: https://www.jstage.jst.go.jp/article/ ctr/12/1/12_133/_article. Acesso em: 1 nov. 2016.
Este é um artigo de acesso aberto distribuído sob os termos de uma Licença Creative Commons Atribuição 4.0 Internacional. Disponível em: <http://creative commons.org/licenses/by/4.0>.

This is an open-access article distributed under the terms of the Creative Commons Attribution License 4.0 International. Available at: <http://creative commons.org/licenses/by/4.0>.

Ce texte en libre accès est placé sous licence Creative Commons Attribution 4.0 International. Disponible sur: <http://creativecommons.org/licenses/by/4.0>.

Recebido: $26 / 06 / 2020$

Aceito: 06/09/2020

Aprovado para publicação: 10/12/2020 